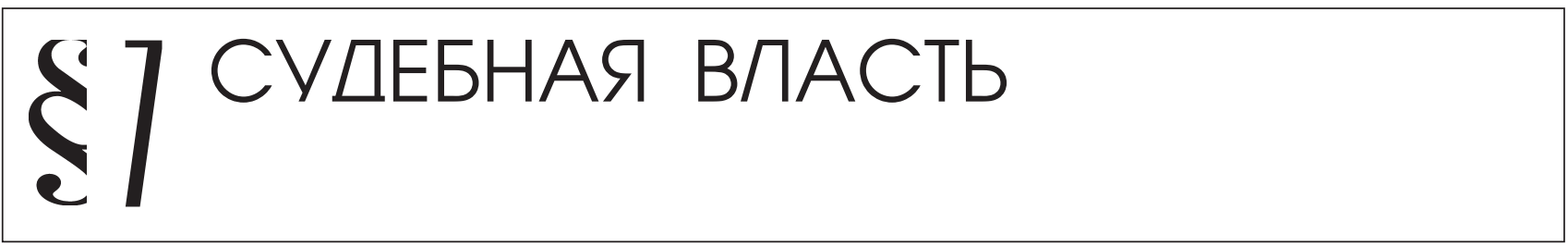

Винокуров А.Ю.

\title{
ПОСТАНОВЛЕНИЕ КОНСТИТУЦИОННОГО СУДА РОССИЙСКОЙ ФЕДЕРАЦИИ ОТ 17 ФЕВРАЛЯ 2015 № 2-П И ЗНАЧИМОСТЬ ЕГО РЕЗОЛЮТИВНОЙ ЧАСТИ ДЛЯ ТЕОРИИ И ПРАКТИКИ ПРОКУРОРСКОГО НАДЗОРА
}

\begin{abstract}
Аннотация: Предметом изучения в рамках настоящей статьи послужили положения резолютивной части постановления Конституиионного Суда Российской Федерации от 17.02.2015 № 2-П. который на основании изучения жалоб заявителей по результатам проведенного заседания изложил ряд принципиальных позиций, которые призваны предопределить на обозримую перспективу направления развития науки о прокурорской деятельности в части прокурорского надзора, а также повлиять на корректировку правоприменительной практики в деятельности прокуроров, осуществляющих надзор за исполнением законов. В процессе изучения основных тезисов резолютивной части рассматриваемого постановления автором сопоставляется позиция Конституционного Суда Российской Федерачии со сложивщейся правоприменительной практикой, а также с теоретическими взглядами в прокурорской науке. Основные выводы проведенного исследования сводятся к тому, что конституиионный Суд Российской Федерации в своем решении подтвердил правомерность ряда сложившихся к настоящему времени моделей поведения прокуроров при осуществлении надзора за исполнением законов, а в некоторых вопросах даже вышел за рамки ожидаемого. В то же время полезными являются и высказанные им требования по совершенствованию законодательства. регламентирующего вопросы проведения прокурорами проверок.

Ключевые слова: Законность, исполнением законов, Конституционный Суд, органы прокуратуры, полномочия прокурора, постановление, правовая позиция, проверка, прокурор, прокурорский надзор.

Abstract: The subject of this study is the positions of the resolutive part of the ruling No. 2-P of the Constitutional Court of the Russian Federation, which, upon examination of complaints and results of a session, rendered a number of important positions, called to define the vectors of development of science in prosecution for the foreseeable future, as well as influence the correction of law enforcement practice in the work of prosecutors carrying out the oversight of law obedience. In the process of studying the key positions of the resolutive part of the examined ruling, the author compares the position of the Constitutional Court of the Russian Federation with the current law enforcement practice, as well as the theoretical views within prosecution. The main conclusions of the conducted research come to the fact the Constitutional Court of the Russian Federation in its ruling confirmed the legality of a number of current behavioral models of prosecutors in carrying out oversight of law obedience, and in some instances even exceeded expectations.
\end{abstract}

Keywords: Lawfulness, Law obedience, Constitutional Court, Prosecutor's office, Prosecutor's power, Ruling, Legal position, Inspection, Prosecutor, Prosecutor's supervision.

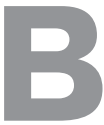

ынесенноеКонституционным Судом Российской Федерации (далее - Конституционный Суд РФ или Суд) постановление от 17.02.2015 № 2-П «По делу о проверке конституционности положений пункта 1 статьи 6 , пункта 2 статьи 21 и пункта 1 статьи 22 Федерального закона "О прокуратуре Российской Федерации" в связи в связи с жалобами межрегиональной ассоциации правозащитных общественных объединений "АГОРА", межрегиональной общественной орга- низации "Правозащитный центр "Мемориал", международной общественной организации "Международное историко-просветительское, благотворительное и правозащитное общество "Мемориал", региональной общественной благотворительной организации помощи беженцам и вынужденным переселенцам "Гражданское содействие", автономной некоммерческой организации правовых, информационных и экспертных услуг "Забайкальский правозащитный центр", региональ- 
DOI: $10.7256 / 1811-9018.2015 .10 .15228$

При цитировании этой статьи сноска на dоі обязательна

\section{Право и политика 10 (190) • 2015}

ного общественного фонда "Международный стандарт" в Республике Башкортостан и гражданки С.А. Ганнушкиной» (далее - Постановление № 2-П) [1] явилось в принципе ожидаемым событием с учетом того, что нормы Федерального закона от 17.01.1992 № 2202-1 «О прокуратуре Российской Федерации» (далее - Закон о прокуратуре) [2], регламентирующие вопросы осуществления надзора за исполнением законов, достаточно давно вызывают неоднозначную реакцию как в прокурорской среде, так и у представителей поднадзорных органам прокуратуры структур, поскольку в силу своей лаконичности и связанным с этим отсутствием конкретности не могут не давать простор для усмотрения в деятельности прокуроров, что в свою очередь вызывает нередко справедливые вопросы у представителей проверяемых органов и организаций.

В рассматриваемом судебном решении тщательной оценке подверглись положения трех указанных в названии документа статей Закона о прокуратуре с учетом толкования, которое их применению придается на практике прокурорами. Поскольку в своей предыдущей публикации [3] мы уделили внимание анализу наиболее значимых тезисов описательной части Постановления № 2-П, в рамках настоящей статьи полагаем необходимым обратиться к сущности его постановочной (резолютивной) составляющей, которая согласно ст. 79 Федерального конституционного закона от 21.07.1994 № 1-ФКЗ «О Конституционном Суде Российской Федерации» [4] обжалованию не подлежит и действует непосредственно.

1. Пунктом 1 резолютивной части взаимосвязанные положения п. 1 ст. 6, п. 2 ст. 21 и п. 1 ст. 22 Закона о прокуратуре признаны не противоречащцми Конституции Российской Федерации (далее - Конституция России) постольку, поскольку эти положения - как закрепляющие полномочие прокурора требовать при проведении проверок в порядке осуществления функции надзора за исполнением законов безусловного представления руководителями и другими должностными лицами некоммерческих организаций необходимых документов, материалов, статистических и иных сведений - обеспечивают выполнение прокуратурой Российской Федерации (далее - прокуратура РФ) возложенной на нее функции надзора как деятельности, обусловленной по своему предназначению требованиями Конституции России, и направлены на обеспечение законности, государственной и общественной безопасности, защиту прав и свобод других лии, а также иных конституционно значимых ценностей.
Приведенный пункт решения со всей очевидностью призван поддержать высокое реноме осуществляемой прокурорами функции прокурорского надзора в части наиболее значимой ее отрасли - надзора за исполнением законов. Действительно, в отличие от неспокойных 1990-х гг., когда не без подсказки зарубежных представителей англосаксонской модели строительства прокуратуры, подразумевающей роль прокурора как должностного лица, осуществляющего уголовное преследование, поборниками либеральных ценностей открыто высказывалась идея упразднения «общего надзора», в том числе и по мотиву того, что и помимо прокуратуры существует множество органов, осуществляющих контрольно-надзорную деятельность. Однако, начиная с 2000 г. потенциал прокуратуры при осуществлении надзора значительно усилился, что объективно объясняется ее востребованностью в рамках построения демократического правового государства, в силу чего, Конституционный Суд РФ занял позицию, несколько, как нам представляется, гипертрофирующую институт прокурорского надзора, что, собственно говоря, и выразилось в отмеченной обусловленности рассматриваемой функции конституционным предназначением прокуратуры РФ.

Безусловность представления перечисленных выше документов основана на положении п. 1 ст. 6 Закона о прокуратуре, однако сам перечень представляемого почему-то приведен из п. 1 ст. 22 названного законодательного акта. На наш взгляд, для полноты восприятия следовало бы назвать также справки и копии документов, указанные в п. 2 ст. 6 Закона о прокуратуре, хотя он и не был предметом судебного рассмотрения.

Несколько гротескно, хотя это в полной мере отвечает избранной в решении линии на поддержку надзорной деятельности прокуроров, выглядит подчеркнутое предназначение прокурорского надзора, который, по мнению Суда, направлен на обеспечение законности, государственной и общественной безопасности, защиту прав и свобод других лиц, а также иных конституционно значимых ценностей. Безусловно, это присутствует в повседневной деятельности прокуроров, однако полагаем, что требуемый эффект был бы по крайней мере не меньше и при ссылке на п. 2 ст. 1 Закона о прокуратуре, относящего к целям деятельности прокуратуры РФ обеспечение верховенства закона, единства и укрепления законности, защиты прав и свобод человека и гражданина, а также охраняемых законом интересов общества и государства.

2. Весьма многосоставным по своей сути, содержащим сразу шесть констатаций, является пункт 
2 резолютивной части, которым также признаны непротиворечащими Конституции РФ положения перечисленных выше статьей Закона о прокуратуре. Рассмотрим соответствующие подходы по порядку.

Во-первых, конституционность п. 1 ст. 22 Закона о прокуратуре предполагает проведение органами прокуратуры проверок исполнения законов некоммерческими организациями в пределах определенного предмета конкретной проверки, обусловленного наличием сведений, указывающих на признаки нарущений законов в деятельности некоммерческой организации и ее должностных лиц (что корреспондирует п. 2 ст. 21 Закона о прокуратуре), которые нельзя подтвердить или опровергнуть в ходемежведомственного взаимодействия (имеется ввиду п. 2 ст. 6 Закона о прокуратуре) с государственным органом, осуществляющим федеральный государственный надзор за деятельностью некоммерческих организаций (далее-Минюст России), с вынесением о том мотивированного решения, подлежащего доведению до сведения проверяемой некоммерческой организации, по крайней мере, в момент начала проверки.

Поясним, что основанием для проведения прокурором проверки в силу п. 2 ст. 21 Закона о прокуратуре является поступившая в органы прокуратуры информация о фактах нарушения законов, требующих принятия мер прокурором. В свою очередь, пункт 1 ст. 22 названного законодательного акта прямо относит к полномочиям прокурора право проверять исполнение законов в связи с поступившей в органы прокуратуры информацией о фактах нарушения закона.

Упоминание о межведомственном взаимодействии с органами Минюста России связано с тем, что проверка исполнения законов прокурором могла бы и не проводится, если бы он путем предъявления требования к указанным государственным органам получил от них достаточную информацию о состоянии законности в деятельности в данном случае некоммерческой организации, позволяющую дать ей полную и объективную оценку.

Однако, наиболее важным, по нашему мнению, является позиция Суда относительно необходимости вынесения прокурором мотивированного рещения о проведении проверки, которое должно доводиться до сведения проверяемой организации не позднее начала проверки. Это обстоятельство является весьма актуальным, придает прокурорской проверке больше официальности и в то же время открытости, исключает использование широко распространенной «партизанской» тактики, суть которой как нельзя лучше переда- ется известным изречением «пришел, увидел, победил».

Во-вторых, конституционность п. 1 ст. 6 и п. 1 ст. 22 Закона о прокуратуре предполагают возможность запроса прокурором у руководителей и должностных лиц некоммерческой организации документов и материалов, непосредственно обусловленных целями и предметом конкретной проверки, которые не могут быть получены у других государственных органов или из открытых источников и не передававшихся органам прокуратуры в связи с ранее проведенной проверкой исполнения законов данной некоммерческой организацией, и не обязывают некоммерческую организацию представлять документы, которые она не обязана иметь в соответствии с законодательством, а также формировать документы, не имеющиеся на момент предъявления требования прокурора.

Приведенный тезис подтверждает уже занятую руководством Генеральной прокуратуры Российской Федерации позицию, предписывающую прокурорам «не допускать факты возложения на контролирующие и иные органы (статистики и др.), а также организации и их должностных лиц обязанности по представлению в органы прокуратуры сведений, не относящихся к предмету проверки либо выходящих за ее пределы, а также не предусмотренных законодательством статистических данных» [5]. Вместе с тем возведение указанных ограничений, которые мы в одной из публикаций охарактеризовали как «фактор сдерживания» [6], в ранг решения Конституционного Суда РФ придает им уже не внутриведомственный, а общеприменимый и однозначно понимаемый всеми статус. Важным дополнением к уже имеющимся ограничениям является позиция Суда относительно отсутствия обязанности у поднадзорного органа (организации) формировать документы, которые, в принципе у него должны быть, но на момент предъявления требования прокурора отсутствуют. Речь может идти о той же статистической отчетности, которая формируется с определенной периодичностью, например, раз в полугодие, а прокурору вдруг потребовалось получить данные за квартал. То же самое можно сказать и об итоговых справках, которые не должны составляться по требованию прокурора раньше установленных внутри конкретного ведомства сроков.

В-третьих, пункт 1 ст. 21 и п. 1 ст. 22 Закона о прокуратуре являются конституционными постольку, поскольку не допускают проведение органами прокуратуры в отношении некоммерческой организации повторной проверки, осуществляемой в связи с фактами, указывающими на предполагаемые нарушения за- 
DOI: $10.7256 / 1811-9018.2015 .10 .15228$

При цитировании этой статьи сноска на dоі обязательна

\section{Право и политика 10 (190) • 2015}

конов, которым по итогам ранее проведенной проверки уже была дана или должна была быть дана правовая квалификация, за исключением проверки устранения нарушений законов, проводимой в разумный после их выявления срок.

Значение этого положения весьма высоко в силу следующих обстоятельств. С одной стороны, Конституционный Суд РФ четко высказался о запрете прокурорам проводить проверки по уже проверенным ранее фактам либо по фактам, которые являлись на момент проведения предыдущей проверки известными прокурорам, но в силу каких-то субъективных причин не получили с его стороны надлежащей оценки. Это означает, что без наличия ставших известными прокурору новых обстоятельств проверка на одном и том же объекте невозможна. Таким образом, исключается вероятность проведения проверочных мероприятий, например, более опытным прокурорским работником, который увидел очевидные огрехи в работе своего коллеги, а также со стороны вышестоящего органа прокуратуры, пожелавшего в порядке оказания методической помощи нижестоящему прокурору выявить его недоработки путем проведения повторной проверки.

Здесь, однако, необходимо иметь ввиду, что данное обстоятельство не должно распространяться на возможность проверки вышестоящей прокуратурой жалобы заявителя на непрофессиональную проверку его доводов нижестоящей прокуратурой, поскольку в противном случае теряется смысл в обращении к вышестоящему прокурору.

Вместе с тем особое значение в рассматриваемой позиции Суда имеет санкционирование им проверки устранения нарушений законов, которая должна проводиться в разумный срок после их выявления. На практике такое направление проверочной деятельности имеет широкое распространение и одобрение Конституционным Судом РФ такого подхода легитимирует его, позволяя более настойчиво добиваться реального устранения нарушений законов, а также своевременно ставить вопрос об ответственности должностных и иных лиц, умышленно не выполняющих законные требования прокурора.

В-четвертых, конституционность п. 1 ст. 22 Закона о прокуратуре усматривается в возможности привлечения прокурором к участию в проведении проверки исполнения законов некоммерческой организацией представителей (сотрудников) других государственных органов лишь в целях осуществления ими вспомогательных (экспертно-аналитических) функций, что исключает самостоятельное проведение провероч-
Hblx действий от имени и в рамках компетенции соответствующих государственных органов и не допускает иных отступлений от установленных действующим законодательством порядка и периодичности проводимых уполномоченными органами государственного контроля (надзора) плановых мероприятий.

Как известно, пунктом 1 ст. 22 Закона о прокуратуре к полномочиям прокурора отнесено его право требовать от руководителей поднадзорных органов выделения специалистов для выяснения возникиих вопросов. Данная норма дословно предусматривает, что прокурор реализует это полномочие, когда непосредственно приходит на проверяемый объект. Вместе с тем правоприменительная практика в немалой степени идет по пути привлечения прокурором в ходе проведения проверки представителей других органов и организаций, преимущественно осуществляющих контрольно-надзорную деятельность. При этом статус таких специалистов законодательно не обозначен, что приводит на практике к фактическому осуществлению ими проверочных мероприятий.

Рассматриваемая позиция Суда ставит вне закона подобные эксцессы, безапелляционно определяя роль соответствующих работников как осуществляющих исключительно экспертно-аналитическую работу.

В-пятых, конституционность п. 2 ст. 21 и п. 1 ст. 22 Закона о прокуратуре рассматривается через призму обязанности органов прокуратуры утверждать по итогам проверки исполнения законов некоммерческой организацией $\boldsymbol{a \kappa m}$, содержащий констатацию наличия или отсутствия в ее деятельности нарушений законов, в связи с возможностью которых осуществлялась прокурорская проверка, и доводить такой акт до сведения проверяемой некоммерческой организации.

Указанная позиция предполагает внесение в надзорную практику дополнительного элемента - документа, подводящего итог проведенной проверке. Это логически корреспондирует высказанному выше подходу о необходимости принятия решения, инициирующего проверку. Требование о составлении резолютирующего акта, как известно, является в настоящее время обязательным в деятельности органов государственного контроля (надзора) и муниципального контроля при проведении ими проверок. В этой связи возложение аналогичной обязанности на прокуроров призвано, с одной стороны, упорядочить их проверочную деятельность, исключив из нее присутствующие на практике элементы стихийности, а, с другой, дать в руки проверяемым документ, подтверждающий наличие или отсутствие признаков незаконности в их деятельности. 
Это в свою очередь будет позволять апеллировать к актам прокурорского реагирования, в которых могут отражаться нарушения, не нашедшие закрепления в акте, составленном по итогам проверки.

Безусловно, возложение на прокуроров подобной обязанности «работать по-взрослому» приведет к некоторому снижению результативности (цифровых показателей) надзорной работы, однако необходимость введения более жестких правил, регламентирующих надзорный процесс, не вызывает сомнений. В какой-то степени моральное удовлетворение от рассматриваемой позиции Суда получат контрольно-надзорные органы, в деятельности которых регулярно находят малейшие отклонения от требований закона сами прокуроры.

В-шестых, конституционность п. 1 ст. 6, п. 2 ст. 21 и п. 1 ст. 22 Закона о прокуратуре предполагают судебную проверку по заявлению некоммерческой организации законности проведения в отношении нее мероприятий прокурорского надзора, принимаемых в ходе этих мероприятий решений, а также связанных с ними действий (бездействия) прокурора, притом что бремя доказывания правомерности проведения проверки и предъявленных требований лежит на прокуроре.

Хотя в последние годы решения и действия (бездействие) прокуроров становятся предметом рассмотрения в судах в связи с жалобами лиц, чьи права и законные интересы, по их мнению, затрагиваются в процессе осуществления прокурорского надзора, необходимость легитимации возможности обращения с жалобой в суд по рассматриваемому поводу очевидна. Не вызывает сомнения необходимость последующего внесения соответствующей нормы в Закон о прокуратуре. В этой связи важным является тезис о том, что бремя доказывания правомерности проведения проверки и предъявленных требований лежит на самом прокуроре. Это стандартный подход при рассмотрении судами дел, вытекающих из публичных правоотношений, и с учетом вступления в силу с 15 сентября 2015 г. Кодекса административного судопроизводства Российской Федерации от 08.03.2015 № 21-Ф3 [7] следует прогнозировать достаточно широкую судебную практику, связанную с обжалованием законности действий (бездействия) и решений прокуроров.

3. Безусловно, в любой бочке меда всегда можно отыскать ложку дегтя, хотя и ряд приведенных выше позиций, формально признающих конституционность рассмотренных норм, выглядят «оправдательными» лишь с очень большой натяжкой, поскольку во многом не констатируют сложившуюся правоприменительную практику, а скорее подсказывают, какой ей надлежит быть, как это имеет место в случаях с теми же решением о проведении проверки, проведением проверки исполнения требования об устранении нарушений закона и актом по результатам проверки.

В этом смысле носящая «отрицательный» заряд мотивация пункта 3 резолютивной части прямо указывает на недостатки п. 1 ст. 6 и п. 1 ст. 22 Закона о прокуратуре, позволяющие оценивать эти нормы как неконституционные в той мере, в какой эти положения - в нарушение требования формальной определенности закона - не устанавливают общие (предельнье) сроки проведения органами прокуратуры проверки исполнения законов некоммерческими организациями, а также, предусматривая безусловное исполнение требований прокурора, вытекающих из его полномочий по проведению проверки исполнения законов, в установленный срок, нарушение которого в системе действующего правового регулирования предполагает наступление административной ответственности, не регламентируют конкретные сроки исполнения таких требований.

Безоговорочно согласимся с отмеченным отсутствием в ст. 22 Закона о прокуратуре общих (предельных) сроков проведения прокурорами проверки. Законодательное установление таковых наряду с введением обязательности принятия решения о проверке и подготовки акта о результатах ее проведения существенно упорядочит надзорный процесс.

Что касается отсутствия в ст. 6 Закона о прокуратуpe положений, регламентирующих конкретные сроки исполнения требований прокуроров, оставляя этот вопрос на усмотрение прокурора, то основной проблемой в правоприменительной практике все-таки является фактическое неисполнение требований прокурора, а не нарушение установленных им сроков для исполнения. Хотя согласимся, что нередко прокуроры, запрашивая те или иные документы в рамках осуществления надзорной функции, формулируют запрос в стиле «вчера было поздно». С этой точки зрения представляется целесообразным закрепление в Законе о прокуратуре применительно к устанавливаемому сроку обязательного признака «разумности». На это обращается внимание, например, в п. 3.6 приказа Генерального прокурора РФ от 21.06.2013 № 252 «О совершенствовании прокурорского надзора за исполнением федерального законодательства органами государственной власти, местного самоуправления, иными органами и организациями» [8], обязывающем прокуроров «при направлении запросов не допускать случаев установления неоправданно коротких сроков исполнения». 
DOI: $10.7256 / 1811-9018.2015 .10 .15228$

При цитировании этой статьи сноска на доі обязательна

\section{Право и политика $10(190) \cdot 2015$}

Кроме того, никто не мешает адресату прокурорского требования в случае невозможности исполнения его в установленный срок сообщить прокурору об этом с объяснением причины. В такой ситуации едва ли у мирового судьи поднимется рука вынести постановление о наложении административного наказания, предусмотренного ст. 17.7 Кодекса Российской Федерации об административных правонарушениях от 30.12.2001 № 195-Ф3 [9] на лицо, не исполнившее требование прокурора, поскольку будет отсутствовать главное условие наступления административной ответственности - умысел на совершение противоправного деяния.

4. В пункте 4 резолютивной части содержится требование к федеральному законодателю о внесении изменений в Закон о прокуратуре и прежде всего в части определения сроков проведения прокурорами проверок и сроков исполнения проверяемыми структурами требований прокурора, вытекающих из его полномочий, о представлении необходимых документов, материалов, статистических и иных сведений. Данная конкретизация, тем не менее, не снимает с повестки дня вопроса о корректировке рассмотренных выше положений ст. ст. 6,21 и 22 Закона о прокуратуре, признанных с точки зрения смысла, придаваемого им правоприменительной практикой, непротиворечащими Конституции России, а также иных нерассмотренных Судом вопросов, возникающих при применении перечисленных статей. Иначе следует прогнозировать новые обращения в Конституционный Суд РФ.

Подводя итог изложенному, подчеркнем, что позиции, высказанные в Постановлении № 2-П на примере проводимых в отношении некоммерческих организаций надзорных мероприятий, в равной мере относятся к проверкам в любом другом поднадзорном прокурорам органе (организации), а это обусловливает необходимость в серьезной корректировке общей методики осуществления надзора за исполнением законов.

\section{Библиография:}

1. СЗ РФ. - 2015. - № 9. - Ст. 1389.

2. СЗ РФ. - 1995. - № 47. - Ст. 4472 (с послед. изменениями).

3. Винокуров А.Ю. Постановление Конституционного Суда Российской Федерации от 17.02.2015 № 2-П и значимость его описательной части для теории и практики прокурорского надзора //

4. СЗ РФ. - 1994. - № 13. - СТ. 1447 (с послед. изменениями).

5. Пункт 15 приказа Генерального прокурора РФ от 07.12.2007 № 195 «Об организации прокурорского надзора за исполнением законов, соблюдением прав и свобод человека и гражданина» // Законность. - 2008. - № 3 (с послед. изменениями).

6. Винокуров А.Ю. Фактор сдерживания в надзорной деятельности прокурора // Законы России: опыт, анализ, практика. -2011 . - № 3 .

7. СЗ РФ. - 2015. - № 10. - Ст. 1391.

8. СПС «КонсультантПлюс».

9. СЗ РФ. - 2002. - № 1 (ч. 1). - Ст. 1 (с послед. изменениями).

\section{References (transliterated):}

1. Vinokurov A.Yu. Postanovlenie Konstitutsionnogo Suda Rossiiskoi Federatsii ot 17.02.2015 № 2-P i znachimost’ ego opisatel'noi chasti dlya teorii i praktiki prokurorskogo nadzora //

2. Vinokurov A.Yu. Faktor sderzhivaniya v nadzornoi deyatel’nosti prokurora // Zakony Rossii: opyt, analiz, praktika. - 2011. - № 3. 